\title{
The geoecological substantiation of pipelines to collect associated petroleum gas
}

\author{
DA Balashov ${ }^{1}$ \\ 1 Northern Arctic Federal University named after M.V. Lomonosov (Arkhangelsk, Russian Federation) \\ Corresponding author: Dmitry Balashov (balashov24@yandex.ru)
}

Academic editor: Aleksandr I. Malov • Received 5 June 2019 • Accepted 30 July 2019 • Published 28 November 2019

Citation: Balashov DA (2019) The geoecological substantiation of pipelines to collect associated petroleum gas. Arctic Environmental Research 19(3): 106-112. https://doi.org/10.3897/issn2541-8416.2019.19.3.106

\begin{abstract}
Construction and exploitation of the gas pipeline is associated with seriously geoecological risks. The magnitude of risks depends on the kind and value of the impact of influencing factors. The factors of geoecological risk mean to the natural and technical conditions, which influences to probability of occurrence, the value of processes with adverse geoecological consequences, also the size of the expected geoecological damage during the transportation of associated petroleum gas (Gubaidullin and Korobov 2005). Territory near shore of Pechora sea between Bolvanskaya bay and Khaypudyrskaya bay is modern promising center of oil production in region. Ricing of oil production connect with ricing of associated petroleum gas (APG) production and searching of ways of effective utilization APG (instead of burning on torch) is actual challenge. The most promising way is common gathering pipeline system with one center of preparing and utilization of APG. Building and exploitation of pipelines connected with high gejecologilal risks. Evaluation and minimization of geecological risk is actual task.

It is necessary to plan steps to minimizing risks (Day et al. 1998) to design stage to reduce the impact on the environment. The factor's indicators of geoeological risk are distributed unevenly along the gas pipeline. Zoning should help to analyze the distribution of geoecological risk factors and determine territories for activities.
\end{abstract}

\section{Keywords}

Geoecological risks, transportation of associated petroleum gas, zoning of pipeline, minimization of geoecological risks

Copyright Balashov DA. This is an open access article distributed under the terms of the Creative Commons Attribution License (CC-BY 4.0), which permits unrestricted use, distribution, and reproduction in any medium, provided the original author and source are credited. 


\section{Introduction}

Despite the fact that in 2012 a draft law was adopted that establishing a normative indicator for the combustion of APG for an amount not exceeding 5\%, this level has not yet been achieved. Figure 1 shows a graph of changes in the level of beneficial use of APG as a percentage of the volume of extracted APG in Russia in 2011-2015 (Fig. 1) (Knignikov and Ilyin 2017).

There are a number of objective reasons that do not allow utilize of APG effectively in the required quantity. First of all, the difficulties are caused by the preparation of APG. Gas should be prepared before burning in boiler units, gas turbine generators or supply to consumers (GOST5542-2014). Key parameters of APG are: the temperature of the dew point; the mass concentration of hydrogen sulfide; the mass concentration of mercaptan sulfur.

Gas preparation by absorption units requires regeneration of absorbent. Hydrogen sulfide is released during the regeneration of the adsorbent. Utilization of Hydrogen sulfide by burning harms the environment, conversion hydrogen sulfide into elemental sulfur by the process of high-temperature catalytic oxidation at the Klaus unit can be effective only in large gas processing complexes with a production capacity of sulfur about 5000 tons per year [3].

Gas preparingin adsorption unit is efficient for small volumes of gas $(2000 \mathrm{~m} 3 /$ day $)$, but because of difficulties in recycling or regeneration of the spent adsorbent, chemical adsorption isn't so common in oil and gas industry (Mazgarov and Kornetov, 2015).

In view of the above, it's advisable to create a unified APG gathering system. This system should to connect oil fields with a relatively low content of APG (about $250 \mathrm{~m} 3$ of APG per ton of oil) with common center of preparing and utilization of APG. Today, promising center of oil's production are fields named after Roman Trebs and Anatoly Titovand the major consumer of APG in region is gas turbine power plant "South Khylchuyu". The realization of common APG gathering system will require the construction of the «Trebsa - South Khylchuyu» gas pipeline (Mashkin 2011).

Construction and exploitation of the gas pipeline is associated with seriously geoecological risks. The

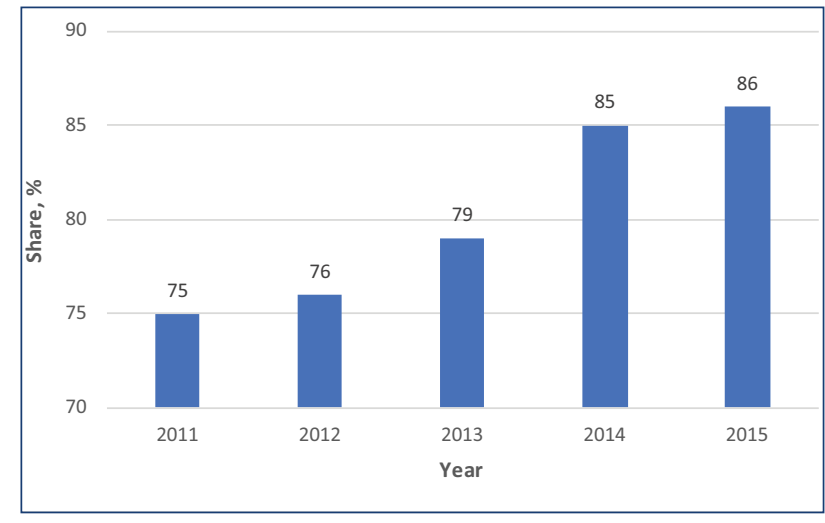

Fig. 1. The level of beneficial use of APG as a percentage of the volume of extracted APG in Russia in 2011-2015

magnitude of risks depends on the kind and value of the impact of influencing factors. The factors of geoecological risk mean to the natural and technical conditions, which influences to probability of occurrence, the value of processes with adverse geoecological consequences, also the size of the expected geoecological damage during the transportation of associated petroleum gas (Gubaidullin and Korobov 2005).

It is necessary to design steps to minimizing the risks of geoecological (Day et al. 1998) at the planning stage to reduce the impact on the environment. The indicators of factors of geoeological risk are distributed unevenly along the gas pipeline. Zoning should help to analyze the distribution of geoecological risk factors and determine territories for activities.

\section{Methods}

There is analysis of the transportation of APG through the pipeline of the central facility "Trebs" to central facility "Yuzhnaya Khylchuyu" in this paper (Gubaydullin, Balashov, 2018). The first option of pipeline goes straight from the central facility "Trebs" to the central facility "South Khylchuyu". The second option located along the lines of the watershed, along the «South Khylchuyu - Varandey oil terminal» oil pipeline at a distance of at least $1000 \mathrm{~m}$ (Fig. 2) (SNiP 2.05.06-85).

Zoning of gas pipeline options is done by an opensource geographic information system (GIS) - QGIS. 


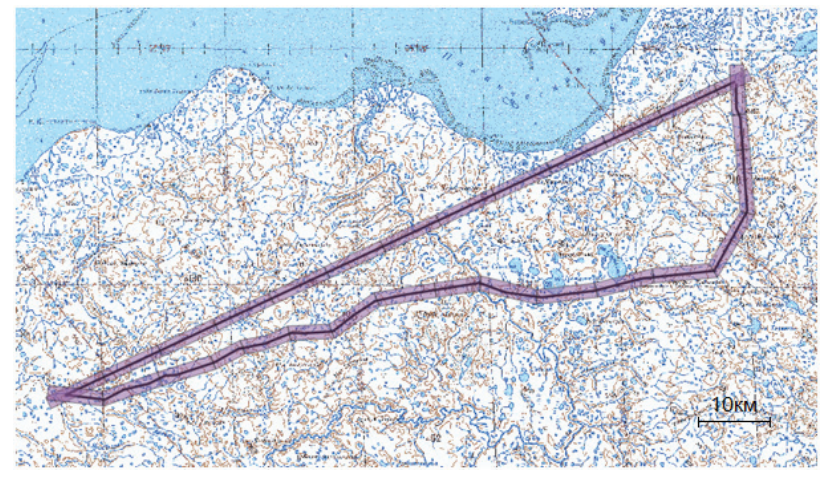

Fig. 2. Scheme of alternative option of pipeline

That is an open source geospatial Foundation (OSGeo) project and is licensed under the GNU General Public License (Graser 2016).

At the first stage of zoning the following schemes were prepared (digitized);

- Scheme of areas affected by cryogenic processes;

- Scheme of rock formations with relatively high bearing capacity (Friedland Sidorenko 1970);

- Scheme of soils relatively resistant to anthropogenic impact (Shishov et. al 1997-2004);

- Scheme of wetlands;

- Scheme of alternative option of pipeline (Fig. 2) (Gubaydullin and Balashov 2018).

Scheme of areas affected by cryogenic processes and Scheme of rock formations with relatively high bearing capacity are based on the data of M. I. Maskov and E. F. Stepanov, 1985.

All schemes were made in projection EPSG:3857 - WGS 84/Pseudo-Mercator (Spherical Mercator) on the sphere (Sidorenko 1970, Baranov et al. 1997), on separate layers. Sheets of maps of the State GIS Center (SGC) scale 1:500000 were used as a basic cartographic basis.

Gas pipeline is a linear object (the length is much greater than the width) and sections in the form of corridors with pipeline in the center are more efficient for zoning. The results of zoning are going to be as realistic as possible, because square of each section is proportional to the length of the pipeline.

The width of corridors is $2 \mathrm{~km}-1 \mathrm{~km}$ on each side of the pipeline. This size of corridor was chosen due to scale of the schemes. The corridors are divided into sections with different length, which depends on the distribution of indicators of geoecological risk factors. In digital form, the plots are separate polygons adjacent to each other.

The most significant factors of geoecological risk from the long list of factors are (Gubaydullin and $\mathrm{Ba}-$ lashov 2018):

- crossings of watercourses and reservoirs;

- composition of the rocks;

- permafrost soils;

- soils.

There isn't factor "the length of the pipeline route" in this paper, because - this factor is important for comparing alternative options of pipeline, but importance of factor is lost during comparing of individual sections.

In order to determine the indicator's value, the polygons of each of the indicator layers were transformed into polygons limited by the borders of the plots. Square of the resulting polygons are equal to the value of the indicators for each plot (Table 1).

It should be noted, that not all the indicators used are equivalent. Indicators: the square of soils relatively resistant to anthropogenic impact and the square of rock formations with relatively high bearing capacity, characterize positively the plots in contrast to others indicators. For a more correct comparison, the above indicators were replaced by the opposite: the square of soils relatively susceptible to anthropogenic impact and the square of rock formations with relatively low bearing capacity. The inverse indicators are those obtained by subtracting the corresponding indicators from the square of the plots.

The indicator "intersections with watercourses" isn't measured by square meters. This indicator is possible to transform to percent to compare this indicator with the rest of the indicator: maximum number of intersections in some plot is $100 \%$, the values for other plots are proportional.

The plot's weights equal to sum of the values of all indicators of this plot. For clarity, the plot's weights are transformed thus that sum of plot's weights equal to 1000 because the weights are too small. 
Table 1. Distribution of indicators of geoecological risk

\begin{tabular}{|c|c|c|c|c|c|c|}
\hline № plot & $\begin{array}{c}\text { Square of areas } \\
\text { affected by } \\
\text { cryogenic processes } \\
\mathrm{km}^{2} / \%\end{array}$ & $\begin{array}{c}\text { Square of soils } \\
\text { relatively resistant to } \\
\text { anthropogenic impact } \\
\mathrm{km}^{2} / \%\end{array}$ & $\begin{array}{c}\text { Square of rock } \\
\text { formations with } \\
\text { relatively high } \\
\text { bearing capacity } \\
\mathrm{km}^{2} / \%\end{array}$ & $\begin{array}{l}\text { Square of wetlands } \\
\qquad \mathrm{km}^{2} / \%\end{array}$ & $\begin{array}{c}\text { Number of } \\
\text { crossings of } \\
\text { pipeline with } \\
\text { watercourses and } \\
\text { reservoirs } \mathrm{km}^{2} / \% \\
\end{array}$ & $\begin{array}{c}\text { Square of plot } \\
\text { p. } / \%\end{array}$ \\
\hline \multicolumn{7}{|l|}{1 option } \\
\hline 1 & $8.6 / 43.4$ & $0 / 0$ & $19.8 / 100$ & $19.8 / 100$ & $1 / 25$ & $19.8 / 31.87$ \\
\hline 2 & $4.6 / 23.4$ & $0.9 / 4.6$ & $19.7 / 100$ & $16.9 / 85.8$ & $3 / 75$ & $19.7 / 34.28$ \\
\hline 3 & $11.9 / 60.4$ & $18.9 / 95.6$ & $5.3 / 26.9$ & $19.7 / 100$ & $1 / 25$ & $19.7 / 36.6$ \\
\hline 4 & $10.3 / 52.6$ & $19.6 / 100$ & $4.5 / 23$ & $2.9 / 14.8$ & $3 / 75$ & $19.6 / 31.5$ \\
\hline 5 & $19.5 / 100$ & $19.5 / 100$ & $19.5 / 100$ & $0.2 / 1$ & $1 / 25$ & $19.5 / 38.71$ \\
\hline 6 & $14.8 / 76.3$ & $19.4 / 100$ & $10.1 / 52.1$ & $1.4 / 7.2$ & $1 / 25$ & $19.4 / 30.94$ \\
\hline 7 & $16.5 / 48.5$ & $5.7 / 29.5$ & $11.5 / 59.6$ & $3.8 / 19.7$ & $1 / 25$ & $19.3 / 26.04$ \\
\hline 8 & $13.7 / 71.4$ & $0.1 / 0.5$ & $19.2 / 100$ & $8.2 / 42.7$ & $1 / 25$ & $19.2 / 28.45$ \\
\hline 9 & $10.5 / 54.7$ & $3.1 / 16.1$ & $19.2 / 100$ & $17.8 / 92.7$ & $3 / 75$ & $19.2 / 40.2$ \\
\hline 10 & $0 / 0$ & $16.4 / 85.4$ & $19.2 / 100$ & $19.2 / 100$ & $4 / 100$ & $19.2 / 45.76$ \\
\hline 11 & $2.1 / 11.1$ & $0 / 0$ & $19 / 100$ & 1052.6 & $0 / 0$ & $19 / 19.44$ \\
\hline 12 & $14.2 / 74.7$ & $6.8 / 35.8$ & $17.3 / 91.1$ & $6.5 / 34.2$ & $2 / 50$ & $19 / 33.93$ \\
\hline 13 & $11.3 / 100$ & $9.9 / 87.6$ & $6.1 / 54$ & $1.9 / 16.8$ & $1 / 25$ & $11.3 / 33.65$ \\
\hline \multicolumn{7}{|l|}{2 option } \\
\hline 1 & $9 / 43.6$ & $0 / 0$ & $20.8 / 100$ & $18 / 86.5$ & $1 / 25$ & $20.8 / 30.26$ \\
\hline 2 & $14.2 / 63.7$ & $0 / 0$ & $22.3 / 100$ & $20 / 89.7$ & $1 / 25$ & $22.3 / 33.05$ \\
\hline 3 & $11.6 / 56.3$ & $20.3 / 98.5$ & $13.8 / 67$ & $20.6 / 100$ & $1 / 25$ & $20.6 / 41.18$ \\
\hline 4 & $9.3 / 75.6$ & $12.3 / 100$ & $0 / 0$ & $4.6 / 37.4$ & $0 / 0$ & $12.3 / 25.29$ \\
\hline 5 & $10.4 / 59.4$ & $17.5 / 100$ & $4.4 / 25.1$ & $0.7 / 4$ & $1 / 25$ & $17.5 / 25.36$ \\
\hline 6 & $13.6 / 86.6$ & $15.7 / 100$ & $6.6 / 42$ & $0.8 / 5.1$ & $1 / 25$ & $15.7 / 30.72$ \\
\hline 7 & $17.9 / 88.2$ & $20.3 / 100$ & $16.3 / 80.3$ & $1.3 / 6.4$ & $1 / 25$ & $20.3 / 32.61$ \\
\hline 8 & $21.9 / 00$ & $21.9 / 100$ & $5.1 / 23.3$ & $1.4 / 6.4$ & $1 / 25$ & $21.9 / 30.24$ \\
\hline 9 & $15.4 / 91.7$ & $16.8 / 100$ & $14.3 / 85.1$ & $0.9 / 5.4$ & $2 / 50$ & $16.8 / 39.44$ \\
\hline 10 & $14.9 / 69.3$ & $15 / 698$ & $21.5 / 100$ & $17.4 / 80.9$ & $2 / 50$ & $21.5 / 43.93$ \\
\hline 11 & $16.2 / 74$ & $1.2 / 5.5$ & $21.9 / 100$ & $12.9 / 58.9$ & $3 / 75$ & $21.9 / 37.21$ \\
\hline 12 & $15.9 / 73.6$ & $21 / 97.2$ & $21.6 / 100$ & $10.8 / 50$ & $1 / 25$ & $21.6 / 41.06$ \\
\hline 13 & 22.3100 & $22.3 / 100$ & $10.4 / 46.6$ & $5.2 / 23.3$ & $1 / 25$ & $22.3 / 35.02$ \\
\hline 14 & $12.3 / 50.4$ & $7.2 / 29.5$ & $24.4 / 100$ & $5.2 / 21.3$ & $1 / 25$ & $24.4 / 26.86$ \\
\hline 15 & $14.2 / 61.5$ & $0.3 / 1.3$ & $23.1 / 100$ & $1.9 / 8.2$ & $2 / 50$ & $23.1 / 26.24$ \\
\hline 16 & $11.6 / 92.1$ & $10 / 79.4$ & $12.4 / 98.4$ & $2.7 / 21.4$ & $1 / 25$ & $12.6 / 37.55$ \\
\hline 17 & $17.7 / 100$ & $7.5 / 42.4$ & $12.1 / 68.4$ & $2.4 / 13.6$ & $1 / 25$ & $17.7 / 29.6$ \\
\hline
\end{tabular}

The weights of plots in Table 1 are not final. Each factor influence differently to the value of geo-environmental risk and the weights should be corrected.

Previously, a expert's survey was conducted and weight coefficients for each factor were determined by the analytic hierarchy process (Korobov 2008). The multiplication of weight factors to appropriate values from Table 1 gives final weights, which are shown in Table 2.

For clarity, the final weights are transformed thus that sum of weights equal to 1000 .

The final weights allow to compare not only particular plots but and options of pipeline. The average weight of geoecological risk for the first option of pipeline equal 34.11, it's greater than the weight of the second option of pipeline which equal 32.74. That means, that volume of geoecological risk distributed along the length of the pipeline for the first option is bigger than for the second, which confirms the previous conclusions which are based on a pair comparison of geoecological risk factors.

Comparing the weights and the final weights of environmental risk shows that they are different, but slightly.

Identification of areas for which activates is necessary to minimize geo-ecological risks require division of plots to groups. 
Table 2. Distribution of geoecological risk indicators taking into account weight coefficients

\begin{tabular}{|c|c|c|c|c|c|c|}
\hline № plot & Cryogenic processes & $\begin{array}{l}\text { Soils relatively } \\
\text { resistant to } \\
\text { anthropogenic } \\
\text { impact }\end{array}$ & $\begin{array}{l}\text { Rock formations } \\
\text { with relatively high } \\
\text { bearing capacity }\end{array}$ & Wetlands & $\begin{array}{c}\text { Crossings of } \\
\text { pipeline with } \\
\text { watercourses and } \\
\text { reservoirs }\end{array}$ & Final weight \\
\hline \multicolumn{7}{|l|}{1 option } \\
\hline 1 & 6.7 & 0.0 & 5.1 & 17.6 & 5.1 & 34.6 \\
\hline 2 & 3.6 & 0.3 & 5.1 & 15.1 & 15.2 & 39.4 \\
\hline 3 & 9.3 & 6.7 & 1.4 & 17.6 & 5.1 & 40.1 \\
\hline 4 & 8.1 & 7.0 & 1.2 & 2.6 & 15.2 & 34.1 \\
\hline 5 & 15.5 & 7.0 & 5.1 & 0.2 & 5.1 & 32.9 \\
\hline 6 & 11.8 & 7.0 & 2.7 & 1.3 & 5.1 & 27.8 \\
\hline 7 & 13.2 & 2.1 & 3.1 & 3.5 & 5.1 & 26.9 \\
\hline 8 & 11.0 & 0.0 & 5.1 & 7.5 & 5.1 & 28.8 \\
\hline 9 & 8.5 & 1.1 & 5.1 & 16.3 & 15.2 & 46.3 \\
\hline 10 & 0.0 & 6.0 & 5.1 & 17.6 & 20.3 & 49.0 \\
\hline 11 & 1.7 & 0.0 & 5.1 & 9.3 & 0.0 & 16.1 \\
\hline 12 & 11.6 & 2.5 & 4.7 & 6.0 & 10.2 & 34.9 \\
\hline 13 & 15.5 & 6.1 & 2.8 & 3.0 & 5.1 & 32.4 \\
\hline \multicolumn{7}{|l|}{2 option } \\
\hline 1 & 6.7 & 0.0 & 5.1 & 15.2 & 5.1 & 32.2 \\
\hline 2 & 9.9 & 0.0 & 5.1 & 15.8 & 5.1 & 35.9 \\
\hline 3 & 8.7 & 6.9 & 3.4 & 17.6 & 5.1 & 41.7 \\
\hline 4 & 11.7 & 7.0 & 0.0 & 6.6 & 0.0 & 25.3 \\
\hline 5 & 9.2 & 7.0 & 1.3 & 0.7 & 5.1 & 23.3 \\
\hline 6 & 13.4 & 7.0 & 2.2 & 0.9 & 5.1 & 28.5 \\
\hline 7 & 13.6 & 7.0 & 4.1 & 1.1 & 5.1 & 31.0 \\
\hline 8 & 15.5 & 7.0 & 1.2 & 1.1 & 5.1 & 29.9 \\
\hline 9 & 14.2 & 7.0 & 4.4 & 0.9 & 10.2 & 36.7 \\
\hline 10 & 10.7 & 4.9 & 5.1 & 14.2 & 10.2 & 45.1 \\
\hline 11 & 11.4 & 0.4 & 5.1 & 10.4 & 15.2 & 42.6 \\
\hline 12 & 11.4 & 6.8 & 5.1 & 8.8 & 5.1 & 37.2 \\
\hline 13 & 15.5 & 7.0 & 2.4 & 4.1 & 5.1 & 34.0 \\
\hline 14 & 7.8 & 2.1 & 5.1 & 3.8 & 5.1 & 23.8 \\
\hline 15 & 9.5 & 0.1 & 5.1 & 1.4 & 10.2 & 26.4 \\
\hline 16 & 14.2 & 5.5 & 5.1 & 3.8 & 5.1 & 33.7 \\
\hline 17 & 15.5 & 3.0 & 3.5 & 2.4 & 5.1 & 29.4 \\
\hline
\end{tabular}

Table 3. Parcel groups

\begin{tabular}{|c|c|}
\hline Group & Weight \\
\hline 1 & $0-28.8$ \\
\hline 2 & $28.9-37.2$ \\
\hline 3 & $37.3-49$ \\
\hline
\end{tabular}

The presented plots can be divided into 3 groups according by the method of natural breaks (Jenks 1976) in the QGIS - Table 3 (Fig. 3).

The first group includes the plots least damaged to environmental risk in relation to others. Activities for minimization of geo-ecological risk are not required for plots from this group, but that is possible if one of

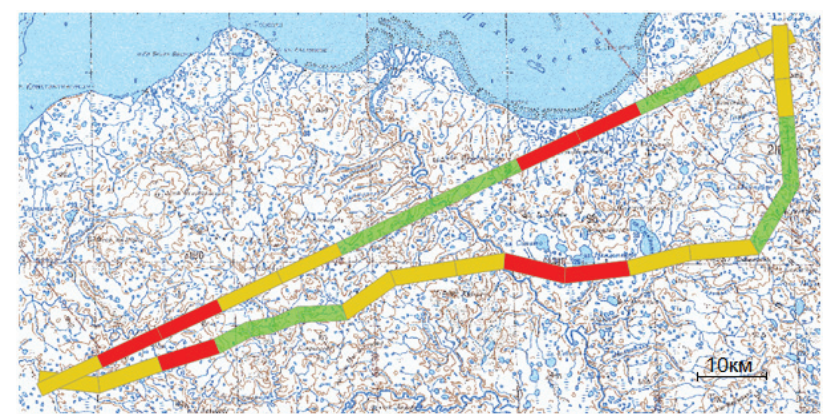

Fig. 3. Distribution of plots by groups of geoecological risk: green colour - first group; yellow colour - second group; red colour - third group the indicators is much higher than others. 
The second group includes plots slightly damaged to geo-ecological risk. Activities for minimization of geo-ecological risk are necessary for plots from this group, to minimizing one or two factors of geo-ecological risk.

The third group includes plots damage to environmental risk. Plots from this group need complex activities to minimize geo-ecological risks aimed at several factors.

The distribution of plots into groups gives information about the scale of the necessary activities to minimize geoecological risks, but it doesn't give information about kind of activities. To do this, it is necessary to identify the major indicators on each of the plots. Analysis of information from Table 3 shows that indicators with an estimate of 10 or more are the most pronounced. Identified indicators help to find out which kind of activities is necessary for every plot.

\section{Results}

1. The geoecological risks associated with low bearing capacity of soils and high susceptibility of soils in all areas are significantly lower than for other factors and do not require special activities.

2. Two plots are not affected by any factors, and do not require special activities to minimize risks.

3. Most plots affected by some factor of geoecological risk and needs some kind of special activities to minimize risks.

4. Only two plots are affected by three factors of geoecological risk and needs complex activities to minimize risks.

\section{References}

- Baranov YK, Gavruk MI, Loginovsky VA, Pescov JA (1997) Navigation - Book for high schools. Saint Petersburg, 511 pp.

- Friedland VM (?) Detailed map of soils of the Russian Federation. Scale: 1:2500000. Soil Institute. V. V. Dokuchaeva.

- GOST5542-2014 "Natural combustible gases for industrial and domestic purposes".

- Graser A (2016) Learning QGIS third edition. PacktPublishing Ltd., Birmingham, 193 pp.

\section{Discussion}

Ricing of oil production in current region trigger with ricing of APG production and require searching of ways of effective utilization APG. The most promising way is common gathering system with one center of preparing and utilization of APG. Choice of pipeline's path is actual task, which require complex analysis of geoecological risk's factors. High differentiation between risk's value for different plots of pipeline require special local activities for risk's minimization. Proposed zoning's system help to find out where special activities are necessary and which kind of activities is necessary for every plot.

\section{Conclusions}

General aim of proposed zoning 's system is evaluation of geoecological risk. Risk's evaluation include evaluation of risk's sum and risk's evaluation by every risk's factor. Factor's weight afford to compere risk's factors between each other.

Zoning system helps to compere alternative options of pipeline by average value of geoecological risk for all plots of pipeline's option, compere different plots of pipeline between each other and find major risk's factors for every plot of pipeline. Geoecological risk's evaluation is base for designs of pipeline which helps to plan special local activities for risk's minimization and find most vulnerable plots of pipeline.
- Gubaidullin MG, Korobov VB (2005) Expert integrated assessment of the ecological state of the geological environment. - Geoecology. Geology Engineering. Hydrogeology. Geocryology (3) 244-252.

- Gubaydullin MG, Balashov DA (2018) Analysis of geoecological risk factors in the transport of associated petroleum gas in the coastal zone of the Pechora sea. Moscow. Russian state University of oil and gas. I. M. Gubkina. Environmen- 
tal Protection in the oil and gas industry 4: 37-42. https://doi. org/10.30713/2411-7013-2018-4-37-42 [In Russian]

- Jenks GF (1976) The Data Model Concept in Statistical Mapping // International Yearbook of Cartography. 7: 186-190.

- Knignikov AY, Ilyin AM (2017) Problems and prospects of using associated petroleum gas in Russia. World Wild life Fund. Moscow, $32 \mathrm{pp}$.

- Korobov VB (2008) Expert methods in geography and Geoecology. Pomor University, Arkhangelsk, 236 pp.

- Mashkin YL (2011) Preliminary evaluation of the environmental impact to the materials of the substantiation of investments into development of gas fields named after Roman Trebs and Anatoly Titov, Bashneft, center for environmental design, engineering and innovation, St. Petersburg, $305 \mathrm{pp}$.
Mazgarov AM, Kornetov OM (2015) Technologies for Purification of Associated Petroleum Gas from Hydrogen Sulfide. University of Kazan, Kazan, 70 pp.

- Day N, Clark J, Kenow K, Hughes R, Willerup P (1998) The choice of route of pipeline for rural and cross-country pipelines. ACCA. Manualandreportsonengineeringpracticeno.46 38.

- Shishov LL, Tonkonogov VD, Lebedev I, Gerasimova MI (1997-2004) Classification of Soil of Russia. Soil Institute named after V. V. Dokuchaev, Moscow, 342 pp.

- Sidorenko AV (1970) Hydrogeology of USSR, adition XLII, Komi ASSR and the Nenets national district of the Arkhangelsk oblast, RSFSR. Ukhta territorial geological Department. Nedra, Moscow, 288 pp.

SNiP 2.05.06-85 (1997) Trunk pipelines, Moscow.

- Svidzinskaya DV, Bruy AC (2014) Basics of QGIS. Kiev, 83 pp. 